\title{
Preparation of ultra-broadband antireflective coatings for amplifier blast shields by a sol-gel method
}

\author{
Huai Xiong ${ }^{1,2}$, Bin Shen ${ }^{1}$, Zhiya Chen ${ }^{1}$, Xu Zhang ${ }^{1}$, Haiyuan $\mathrm{Li}^{1}$, Yongxing Tang ${ }^{1}$, and Lili $\mathrm{Hu}^{3}$ \\ ${ }^{1}$ Key Laboratory of High Power Laser and Physics, Shanghai Institute of Optics and Fine Mechanics, Chinese Academy of Sciences, \\ Shanghai 201800, China \\ ${ }^{2}$ University of Chinese Academy of Sciences, Beijing 100049, China \\ ${ }^{3}$ The Research and Development Center for High Power Laser Glass, Shanghai Institute of Optics and Fine Mechanics, \\ Chinese Academy of Sciences, Shanghai 201800, China \\ (Received 21 July 2017; revised 4 September 2017; accepted 22 September 2017)
}

\begin{abstract}
A type of $\lambda / 4-\lambda / 4$ ultra-broadband antireflective coating has been developed using modified low refractive silica and high refractive silica layers by a sol-gel dip coating method for amplifier blast shields of the Shen Guang II high power laser facility (SG-II facility). Deposition of the first layer (high refractive index silica) involves baking at $200^{\circ} \mathrm{C}$ in the post-treatment step. The second layer (low refractive index, $n=1.20$ ) uses low refractive index silica sol modified by acid catalysis. Thermal baking at temperatures no less than $500^{\circ} \mathrm{C}$ for $60 \mathrm{~min}$ offers chemical stability, ethanol scratch resistance, and resistance to washing with water. The average residual reflection of dual-side-coated fused silica glass was less than $1 \%$ in the spectral range from 450 to $950 \mathrm{~nm}$. Transmission gain has been evaluated by taking into account angular light, and the results show that the transmission gain increases with increasing light incidence. Even at $60^{\circ}$, the transmission spectrum of the broadband antireflective coating effectively covered the main absorption peak of Nd:glass.
\end{abstract}

Keywords: amplifier; antireflective coating; blast shields; sol-gel; ultra-broadband

\section{Introduction}

Sol-gel derived optical coatings are widely used in inertial confinement fusion (ICF) systems. Examples include potassium dihydrogen phosphate (KDP) crystals, quartz glass windows, target lenses and debris shields ${ }^{[1-11]}$. In high power laser systems, blast shields separate the flash lamps from the glass laser slabs to prevent damage to costly amplifiers from possible explosion of flash lamp. With respect to the absorption spectrum of Nd:glass, depending on the operating environment of coated blast shields, the coatings used should be able to exhibit a broadband antireflective (AR) property in the $450-950 \mathrm{~nm}$ wavelength range. They should also possess high abrasion resistance, the ability to withstand flash lamp glow discharges, and high durability. A type of $\lambda / 4-\lambda / 2 \mathrm{SiO}_{2} / \mathrm{Ta}_{2} \mathrm{O}_{5}$ broadband AR coating (BAC), with an expected amplification gain close to $7 \%$ and easily handled coated parts has been designed and developed at the French Alternative Energies and Atomic Energy Commission (CEA) laboratory ${ }^{[12,13]}$, but the transmittance of the

Correspondence to: H. Xiong, Shanghai Institute of Optics and Fine Mechanics, Chinese Academy of Sciences, Shanghai 201800, China.

Email: xhuai1998@siom.ac.cn center wavelength was relatively low $(<97 \%)$. In the $\lambda / 4-$ $\lambda / 2 \mathrm{SiO}_{2} / \mathrm{TiO}_{2} \mathrm{AR}$ coatings used in amplifier blast shields of the SG-II facility for enhancing the pumping efficiency of amplifiers, the average transmission of dual-coated K9 substrates is increased by $6.6 \%$ relative to uncoated substrates in the spectral range from 400 to $700 \mathrm{~nm}^{[14,15]}$. However, such $\lambda / 4-\lambda / 2$ type of coatings (feature M-shape broadband transmission spectrum ${ }^{[15]}$ ) are incapable of covering the main absorption peak of Nd:glass effectively when angular light is taken into account. Compared to the $\lambda / 4-\lambda / 2$ design, $\lambda / 4-\lambda / 4$ BACs feature a flat broadband transmission spectrum $^{[16-18]}$, transmission spectrum can effectively cover the main absorption peak of $\mathrm{Nd}$ :glass.

\section{Experimental section}

Low refractive silica (LRS, $n=1.16$ ) was prepared by mixing teraethoxysilane (TEOS), $\mathrm{H}_{2} \mathrm{O}, \mathrm{NH}_{3}$ and anhydrous ethanol $\left(\mathrm{C}_{2} \mathrm{H}_{5} \mathrm{OH}\right)$ in the molar ratio, 1: 2: 0.9: 34.2, respectively ${ }^{[19]}$. The resulting solution was stirred for $5 \mathrm{~h}$, and aged for at least four days at room temperature. Acid catalyzed silica (ACS) was prepared by mixing TEOS: $\mathrm{H}_{2} \mathrm{O}$ : 


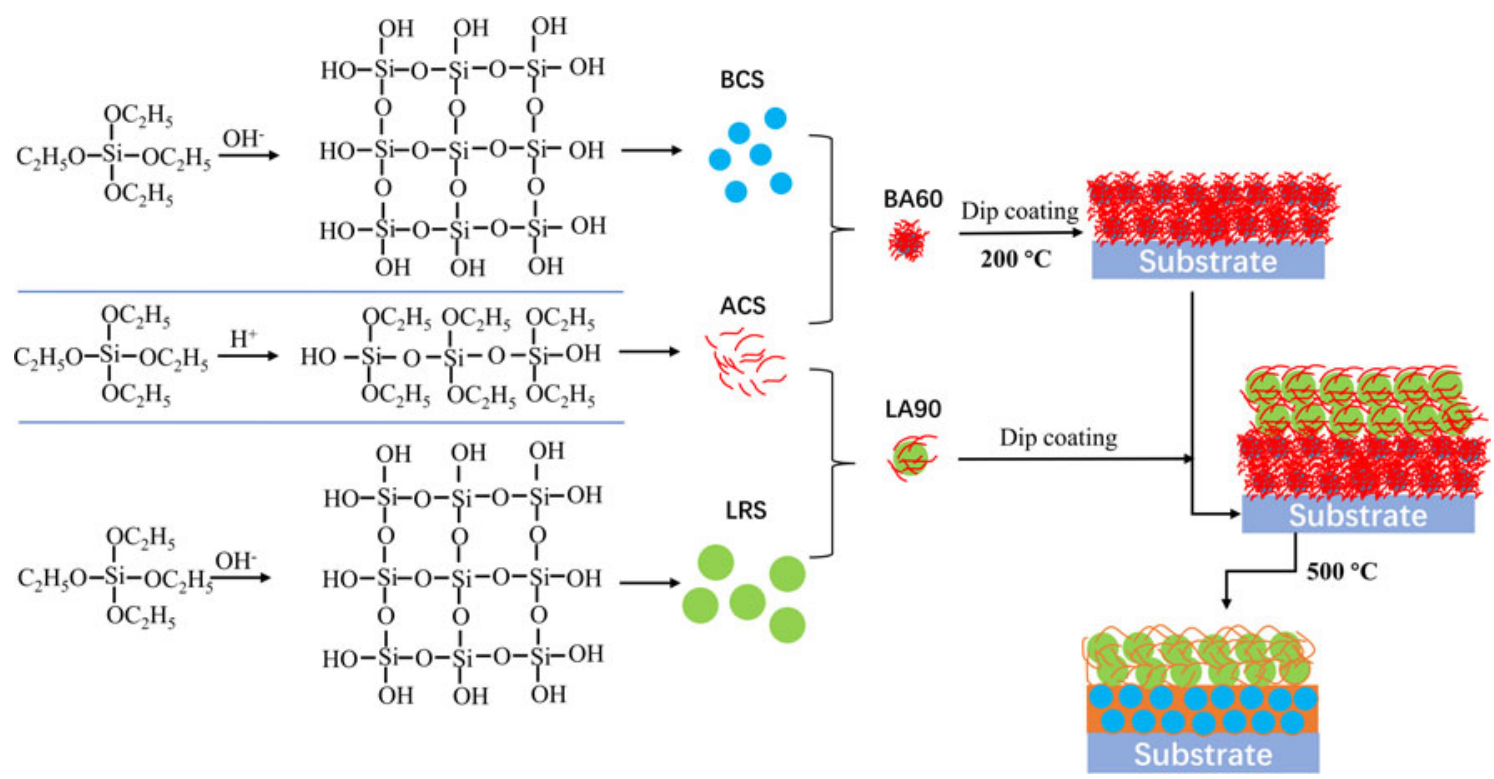

Figure 1. Preparation of ultra-BACs.

hydrochloric acid $(\mathrm{HCl})$ and $\mathrm{C}_{2} \mathrm{H}_{5} \mathrm{OH}$ in the molar ratio, 1:4:0.05:20; the solution was stirred for $4 \mathrm{~h}$, and aged for at least four days at room temperature. Base catalyzed silica (BCS, $n=1.22$ ) was prepared with a molar ratio of TEOS: $\mathrm{H}_{2} \mathrm{O}: \mathrm{NH}_{3}: \mathrm{C}_{2} \mathrm{H}_{5} \mathrm{OH}=1: 2: 0.6: 37^{[7,8]}$. LA90 sol was prepared by mixing LRS and ACS in a molar ratio of 90:10 for $5 \mathrm{~h}$ with vigorous stirring, while BA60 was prepared by mixing BCS and ACS in a molar ratio of 40:60 for $5 \mathrm{~h}$ with vigorous stirring.

Fused silica glass $(50 \mathrm{~mm} \times 60 \mathrm{~mm}, d=2 \mathrm{~mm})$ was coated with BA60 by a dip coating process at a withdrawal speed of $7 \mathrm{~cm} / \mathrm{min}$, and it was baked at $200^{\circ} \mathrm{C}$ for $24 \mathrm{~h}$. Subsequently, the BA60 coated glass was coated with LA90 sol at a withdrawal speed of $7.5 \mathrm{~cm} / \mathrm{min}$, and it was baked at $500{ }^{\circ} \mathrm{C}$ for $1 \mathrm{~h}$ to finally obtain the ultra-BAC. The preparation process of the $\mathrm{SiO}_{2}$ sols is shown in Figure 1. In addition, $\lambda / 4-\lambda / 2 \mathrm{SiO}_{2} / \mathrm{TiO}_{2} \mathrm{AR}$ coatings were prepared according to the process described in Ref. [14, 15].

\section{The optical property of the AR coating}

Ultra-BACs were prepared using the $\lambda / 4-\lambda / 4$ film system. The refractive index $(n)$ of fused silica glass is about 1.45 , therefore a double layer with a refractive index of 1.36/1.20 was selected. The optical transmittance was measured using an ultraviolet-visible-near-infrared (UVVis-NIR) spectrophotometer (Lambda 1050, Perkin-Elmer). The refractive indices and coating thickness $(d)$ of the BA60 and LA90 coating were extracted from the transmission data.

The simulation was carried out with the thin film design software TFCalc. We chose 1.45 as the substrate refractive index and $650 \mathrm{~nm}$ as the center wavelength. The theoretical refractive indices of the double layer were around 1.36 and $1.20(650 \mathrm{~nm})$, and the thicknesses of the double layer were around 119 and $135 \mathrm{~nm}$ that correspond to the optical thickness ( $n d=\lambda / 4$ ). Figure 2 shows the theoretical and experimental transmittance spectra and the absorption spectra of N31 Nd:glass (N31, one type of neodymium doped phosphate glasses, was developed for high peak power laser facility applications in China). The average residual reflection of experimental dual-side-coated fused silica glass is less than $1 \%$ in the spectral region from 450 to $950 \mathrm{~nm}$. However, since the flash lamp can be regarded as a continuous point source, angular light must also be taken into account.

From Figure 3(a), it can be seen that the average residual reflection of fused silica glass coated on both sides with BAC coatings is less than $1 \%$ in the spectral range from 450 to $950 \mathrm{~nm}$ at $0^{\circ}$. Even at $60^{\circ}$, the transmission spectrum of the $\lambda / 4-\lambda / 4$ BAC effectively covers the main absorption peak of Nd:glass. The results show that transmission gain of the BAC increases with light incidence angle by taking into account transmission variation of uncoated fused silica glass [Figure 3(c)]. From Figure 3(b), the $\lambda / 4-\lambda / 2 \mathrm{SiO}_{2} / \mathrm{TiO}_{2}$ BAC (1.90/1.44) can effectively cover the main absorption peak of $\mathrm{Nd}$ :glass at $0^{\circ}$, but transmittance in the wavelength range of $600-700 \mathrm{~nm}$ is lower than 97\%. In addition, with increase in the incident angle, the transmission gain $\left(\mathrm{SiO}_{2} / \mathrm{TiO}_{2}\right.$ coating) of absorption peak in the wavelength range of $500-600 \mathrm{~nm}$ decreases. The $\mathrm{SiO}_{2} / \mathrm{TiO}_{2}$ coatings are incapable of covering the main absorption peak of $\mathrm{Nd}$ :glass effectively when angular light is taken into account. With an increase in the incident angle, both $\mathrm{BAC}$ and $\mathrm{SiO}_{2} / \mathrm{TiO}_{2}$ coating transmittance curves are shifted toward shorter wavelengths. 


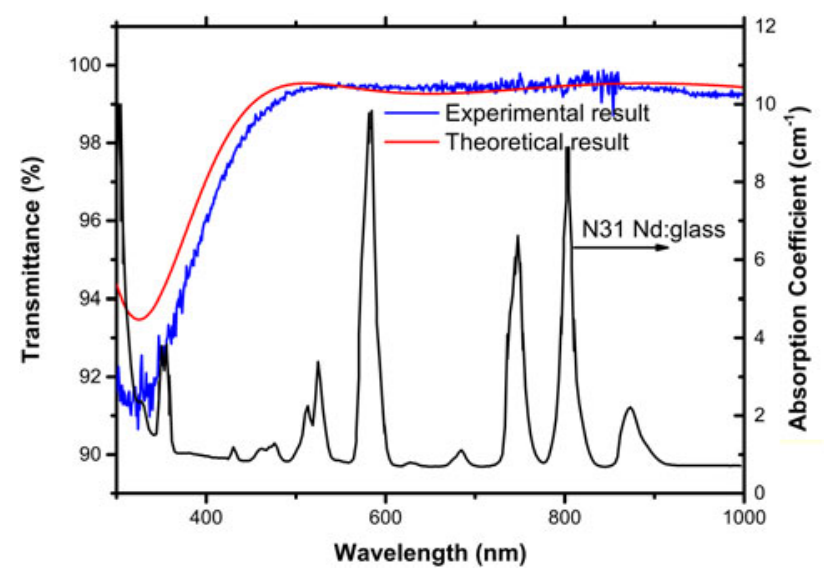

Figure 2. Transmission spectra of ultra-BAC and $\mathrm{N} 31^{[20]} \mathrm{Nd}$ :glass absorption spectra (black curve).

\section{Chemical stability of the coating}

The particle diameter distributions of the sols were measured by dynamic light scattering (DLS) using a Malvern Nano ZS. Figure 4 shows the particle diameter distributions of the sols. The particle diameter $(D)$ of the LRS porous microspheres and linear polymer ACS were 14.2 and $2.3 \mathrm{~nm}$, respectively. LA90 is formed by a small amount linear polymer ACS that twines around the LRS microspheres with a particle diameter of $18.4 \mathrm{~nm}$. When ACS $(D=2.3 \mathrm{~nm})$ is doped with porous microspheres BCS $(D=6.0 \mathrm{~nm})$ with a molar ratio of 60:40, the particle diameter of the resultant BA60 becomes $12.3 \mathrm{~nm}$, almost twice that of BCS. The transmittance curves of the BA60 and LA90 coatings before and after heat treated at $500^{\circ} \mathrm{C}$ (already heat treated $200^{\circ} \mathrm{C}$ ) are shown in Figure 5. After the $500^{\circ} \mathrm{C}$ treatment, the transmittance of the BA60 [Figure 5(a)] coating displays an obvious increase from $95.63 \%$ at $860 \mathrm{~nm}$ to $97.21 \%(n=1.36, d=110 \mathrm{~nm})$ at $600 \mathrm{~nm}$, while the LA 90 coating [Figure 5(b)] shows a small increase from $99.85 \%$ at $700 \mathrm{~nm}$ to $99.99 \%(n=1.20$, $d=123 \mathrm{~nm}$ ) at $590 \mathrm{~nm}$. BA60 contains a large number of linear ACS, and due to the large shrinkage of ACS, which was caused by the high temperature treatment, the BA60 coating loss much of its thickness and shows an obvious increase in transmittance. Due to the main structure of LA90 is nanosilica microspheres LRS, after the high temperature treatment, a few of the linear ACS particles between the LRS microspheres form chemical bonds. The LA90 coating shows slight changes in its thickness and transmittance, and also exhibits an obvious decrease in the contact angle with water. The latter phenomenon is due to the pyrolysis of residual organic groups and surface hydroxylation. Under $500{ }^{\circ} \mathrm{C}$ treatment, the condensation of ethoxyl and hydroxyl groups on the adjacent silica particles form siloxane bond increases the coating's structural strength. This hardening effect increases the coating abrasion resistance and adhesion strength.
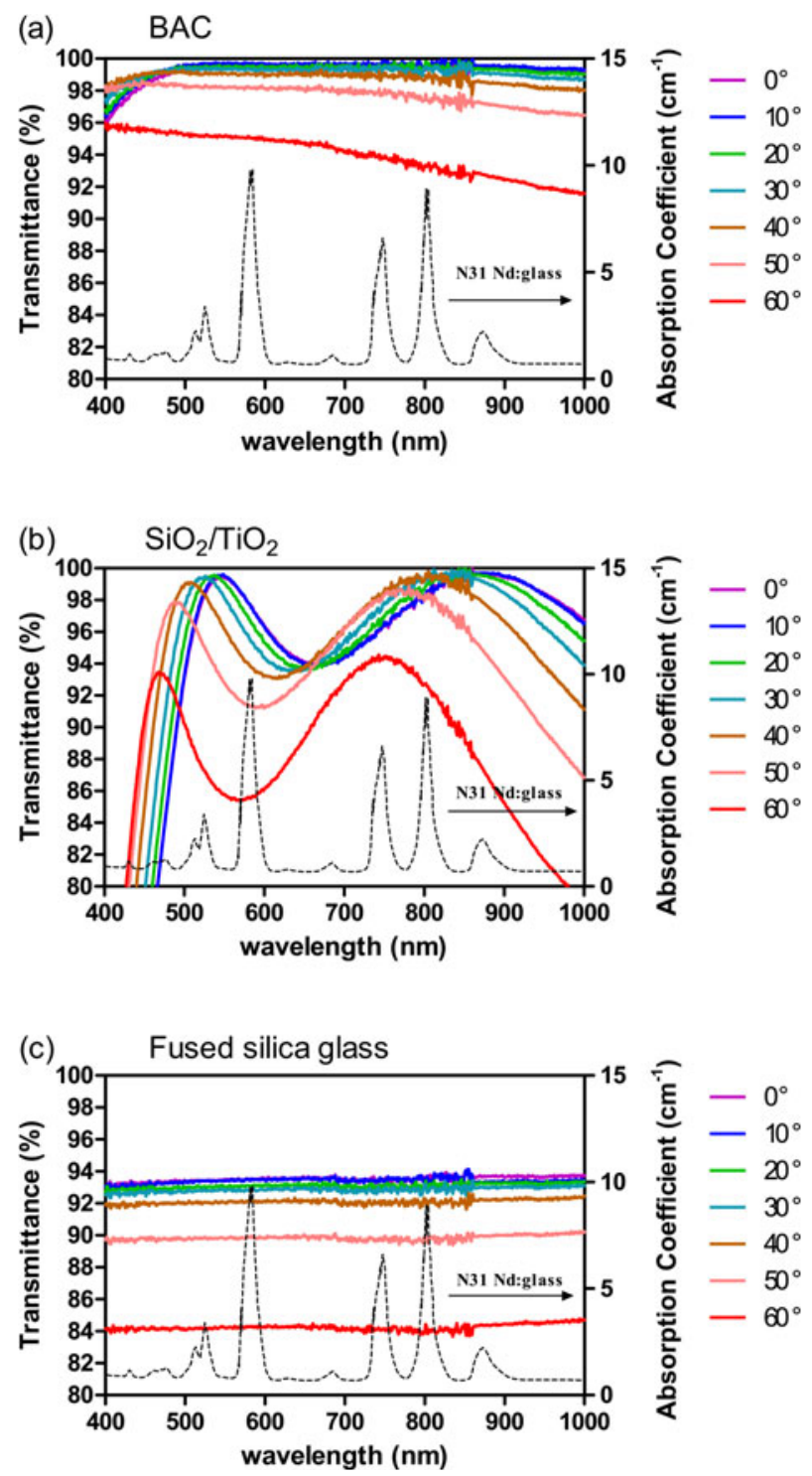

Figure 3. Variation of the transmission spectra with light incidence and $\mathrm{N} 31$ $\mathrm{Nd}$ :glass absorption spectra (black dashed curve). (a) $\mathrm{BACs}$, (b) $\mathrm{SiO}_{2} / \mathrm{TiO}_{2}$ coatings and (c) uncoated fused silica glass.

The $\mathrm{N}_{2}$ adsorption and desorption isotherms of the BAC coatings are measured at $-196^{\circ} \mathrm{C}$. The $\mathrm{N}_{2}$ adsorption and desorption isotherms of the LA90 samples obtained at different heat treatment temperatures each appear as a representative type-IV curve are shown in Figure 6. Both nitrogen isotherms exhibit a typical H2-like hysteresis loop, characteristic of spherical mesopores. The enlarged portion of the low pressure region of LA90 treated at $200{ }^{\circ} \mathrm{C}$ [Figure 6(a)] shows that the high pressure loop remains open down to very low pressures $\left(P / P_{0}<0.2\right)$, the open pressure loop vanishes when the temperature rises to $500{ }^{\circ} \mathrm{C}$ [Figure 6(b)]. The pore diameter distribution from the adsorption data is shown in Figure 6. The pore diameters of LA90 coating after $200^{\circ} \mathrm{C}$ and $500^{\circ} \mathrm{C}$ are 4.9 and $5.2 \mathrm{~nm}$, respectively. 

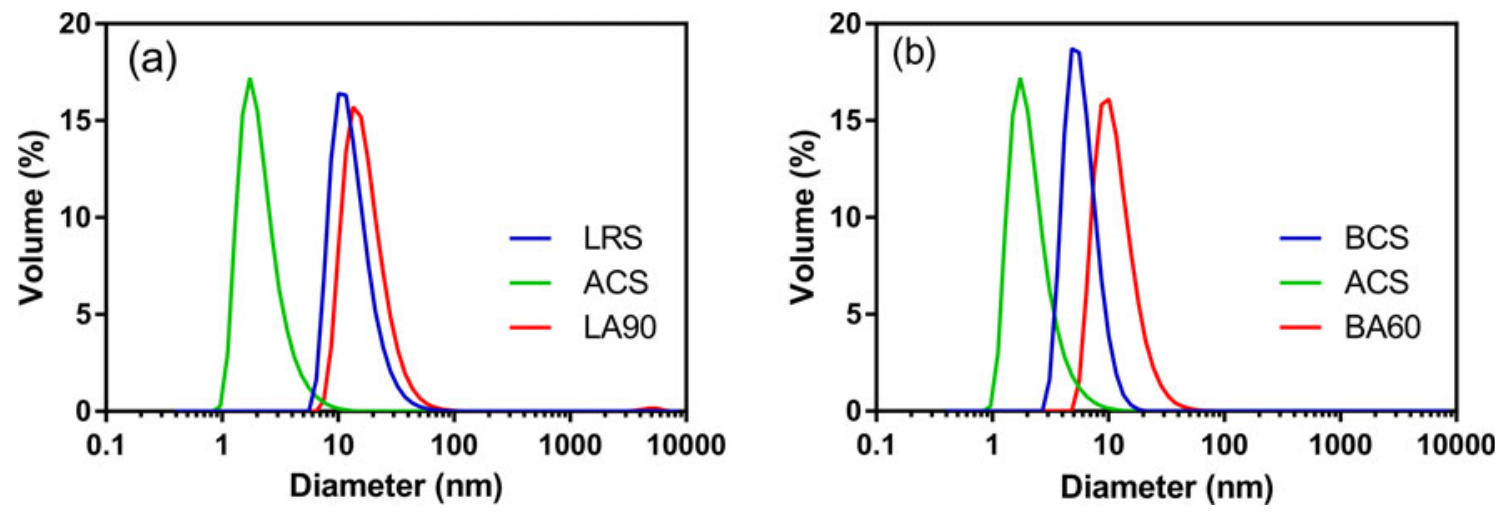

Figure 4. Particle diameter distribution by volume of sols (a) BA60 and (b) LA90.
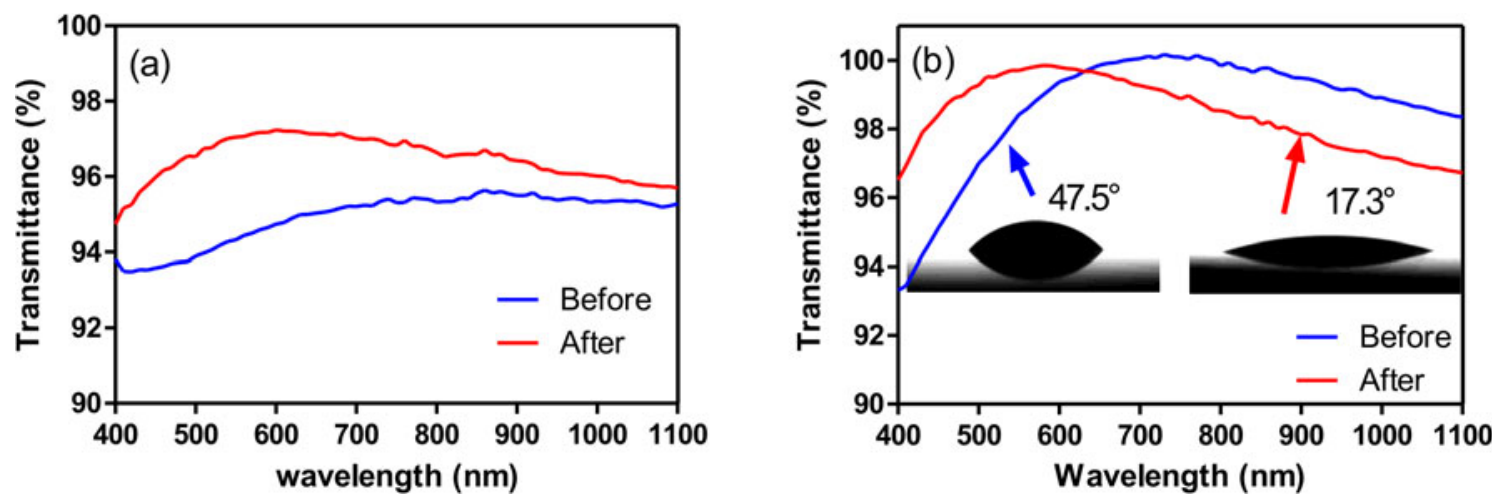

Figure 5. Transmittance of (a) BA60 and (b) LA90 before and after baking at $500^{\circ} \mathrm{C}$.
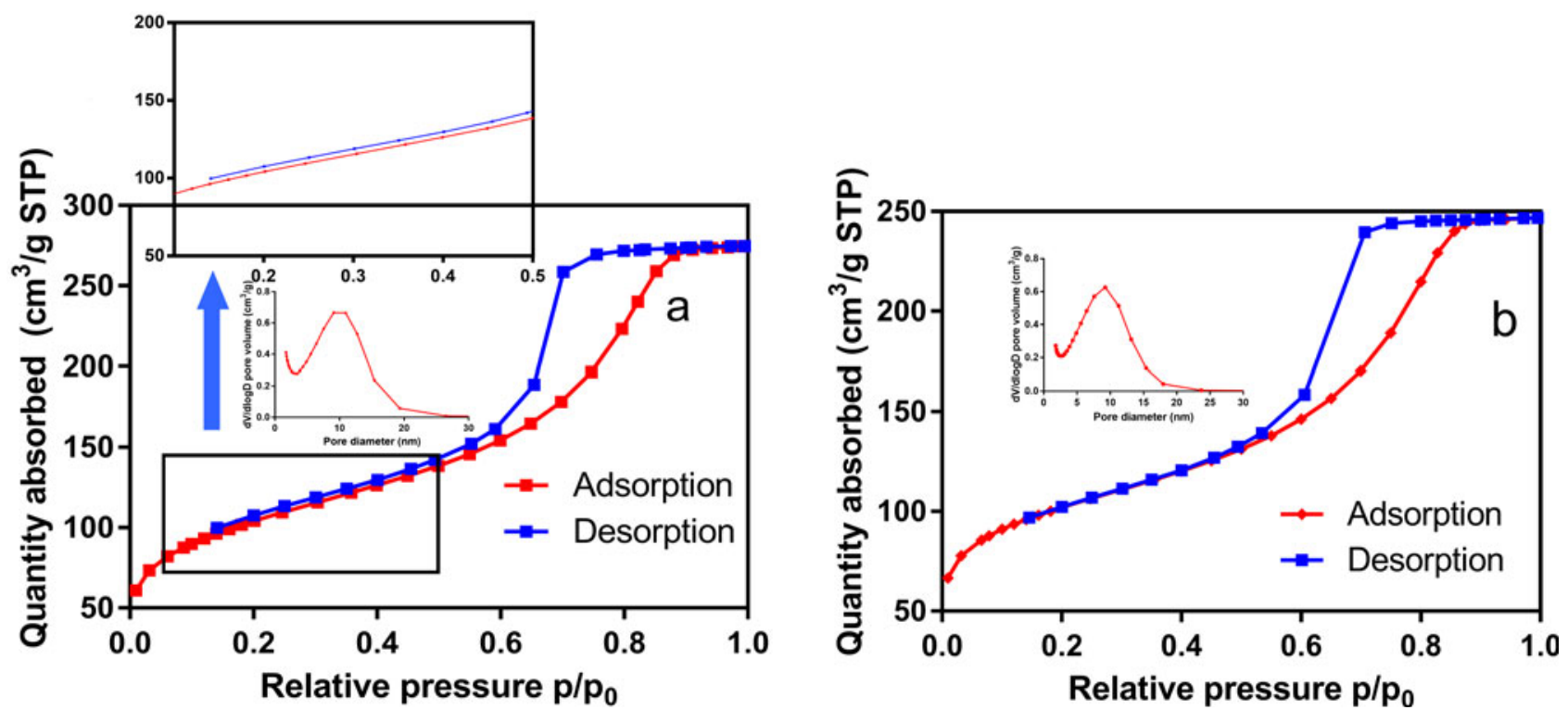

Figure 6. $\mathrm{N}_{2}$ adsorption/desorption isotherm, and pore size distribution curve of LA90 after (a) $200^{\circ} \mathrm{C}$ treatment and (b) $500^{\circ} \mathrm{C}$ treatment.

The sol-gel LA90 coatings consist of a layer of porous silica particles, 10 to $20 \mathrm{~nm}$ in diameter, randomly stacked on the substrate surface, inter-particle voids combine with the particles interior porosity. A possible reason for this phenomenon may be due to partially blocking the pores by chemical species and very narrow particle interior micropores where nitrogen could not escape at the low temperature of the desorption measurement. Perhaps because of 

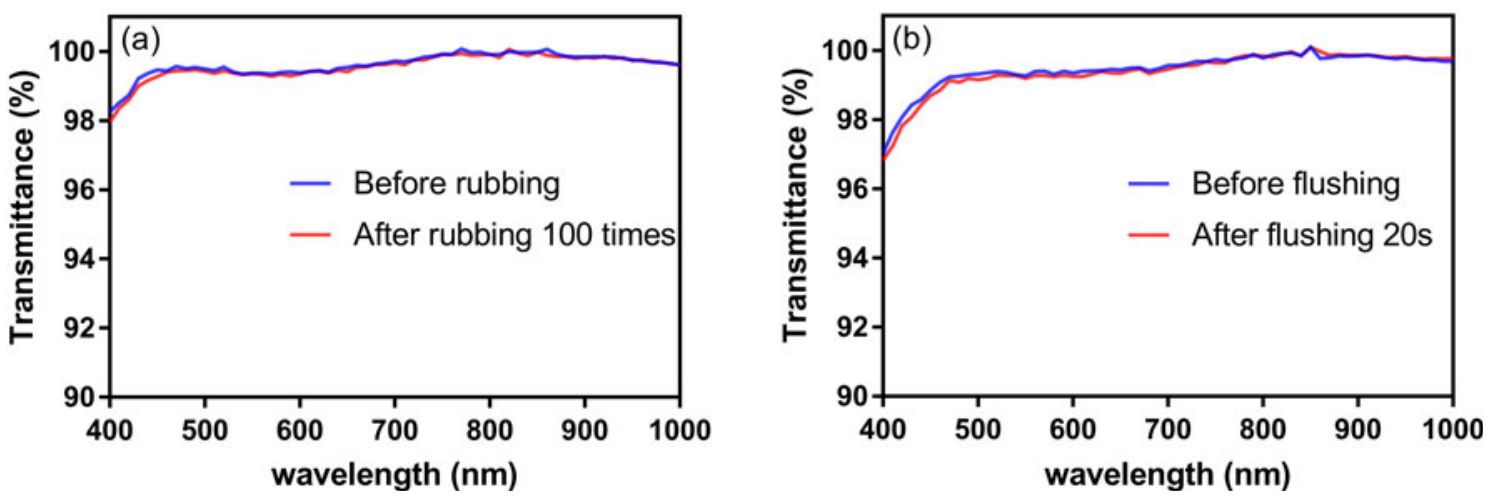

Figure 7. (a) Transmittance of the BAC before and after rubbing by the cotton ball immersed with ethanol 100 times. (b) Transmittance of the BAC before and after deionized water flushing.

the $500^{\circ} \mathrm{C}$ treatment, chemical species were evaporated or decomposed and a small amount of linear polymer ACS that twines around the LRS microspheres shrink and cover the sphere particle, particle interior micropores will not affect $\mathrm{N}_{2}$ adsorption and desorption.

Thus, the chemical stability of the LA90 coating greatly improved after baking at $500^{\circ} \mathrm{C}$.

\section{Scratch resistance}

Since coated amplifier blast shields will be placed in the tiny space between flash lamps and glass laser slabs, the coating needs to withstand two requirements: wiped with ethanol (eliminate fingerprints) and flushed with deionized water (eliminate dust particles).

The mechanical strength of the BAC is greatly enhanced by thermal treatment at $500^{\circ} \mathrm{C}$. As seen in Figure 7(a), the surface of the BAC was rubbed by the cotton ball immersed with ethanol 100 times, the transmission spectra before and after rubbing are very close to each other. The average transmittance after scratching decreased just by $0.057 \%$ (400-1000 nm). Figure 7(b) shows the BAC coating before and after (tested immediately after natural drying) flushing $20 \mathrm{~s}$, the average transmittance decreases by $0.062 \%$. The BAC retains its integrity even wiped with ethanol or flushed with deionized water (Figure 8) proved the coating is adequate for the cleaning requirements for successful longterm use of the blast shield.

\section{Conclusions}

A type of $\lambda / 4-\lambda / 4$ ultra-broadband antireflective coating was designed and developed for amplifier blast shields. The average of residual reflection of dual-side-coated fused silica glass is less than $1 \%$ in the spectral range from 450 to $950 \mathrm{~nm}$. Even at $60^{\circ}$, the transmission spectra of $\lambda / 4-\lambda / 4$ ultra-BACs effectively cover the main absorption peak of

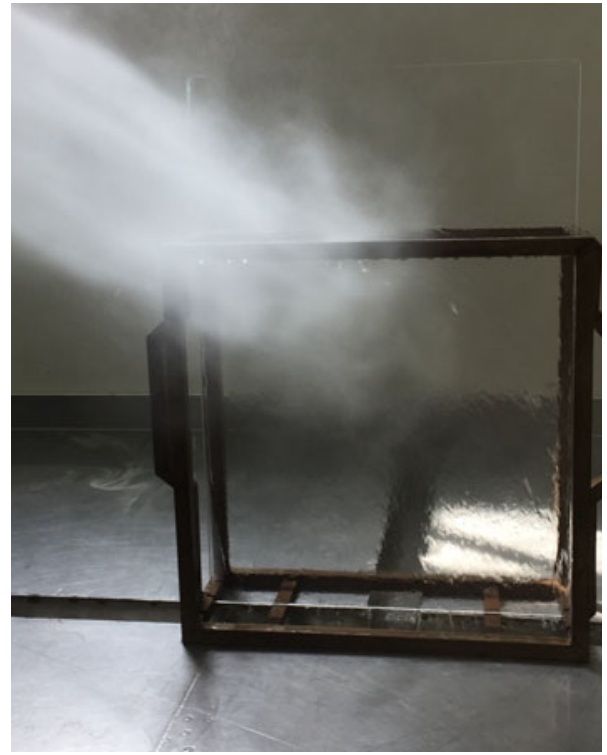

Figure 8. $857 \mathrm{~mm} \times 587 \mathrm{~mm}$ amplifier blast shield with ultra-BAC spray cleaned with deionized water.

Nd:glass. Chemical stability of the coating is greatly improved after baking at $500^{\circ} \mathrm{C}$. The ultra-BAC retains its integrity even when wiped with alcohol or flushed with water.

\section{References}

1. I .M. Thomas, Appl. Opt. 25, 9 (1986).

2. I. M. Thomas, M. R. Kozlowski, G. Edwards, K. Stanion, and B. Fuchs, Proc. SPIE 1441, 137 (1991).

3. Q. Zhang, W. Yang, H. Ma, P. Ma, and Q. Xu, Acta Opt. Sin. 29, 1719 (2009).

4. H. G. Floch and J. J. Priotton, The Physics and Technology of Amorphous $\mathrm{SiO}_{2}$ (Plenum Press, 1988), p. 561.

5. Q. Zhang, L. Zhou, W. Yang, H. Hui, J. Wang, and Q. Xu, Chin. Opt. Lett. 12, 071601 (2014).

6. F. Liu, S. Zhou, W. Dong, and X. Fang, Chin. Opt. Lett. 11, S10211 (2013). 
7. H. Xiong, H. Li, and Y. Tang, Chin. J. Lasers 37, 3116 (2010).

8. H. Li and Y. Tang, Chin. J. Lasers 32, 839 (2005).

9. H. Li, H. Xiong, and Y. Tang, Chin. Opt. Lett. 8, 241 (2010).

10. Y. Tang, H. Xiong, H. Li, and R. Liu, Collect. High Power Laser Plasma Phys. 5, 55 (2007).

11. Y. Tang, W. Zhang, W. Zhou, and C. Zhu, Chin. J. Laser. B3, 469 (1994)

12. P. Belleville and P. Prene, Proc. SPIE 3492, 230 (1999).

13. P. Prené, J. J. Priotton, L. Beaurain, and P. Belleville, J. SolGel Sci. Tech. 19, 533 (2000).

14. Q. Jia, Y. Le, Y. Tang, and Z. Jiang, Acta Opt. Sin. 24, 65 (2004).
15. Q. Jia, Y. Tang, and Y. Le, J. Funct. Mater. 38, 314 (2007).

16. X. Lu, X. Wang, and J. Shen, Rare Metal Mater. Engng 41, 296 (2012).

17. Z. Jie, X. Lu, and Z. Xin, J. Sol-Gel Sci. Technol. 74.1 (2015).

18. X. Cui, R. Ding, M. Wang, C. Wang, J. Zhang, J. Wang, J. Zhang, J. Wang, W. Dong, and Y. Xu, J. Mater. Chem. C 5.12, 3088 (2017).

19. B. Shen, H. Li, H. Xiong, X. Zhang, and Y. Tang, Chin. Opt. Lett. 14, 083101 (2016).

20. L. Hu, S. Chen, J. Tang, B. Wang, T. Meng, W. Chen, L. Wen, J. Hu, S. Li, Y. Xu, Y. Jiang, J. Zhang, and Z. Jiang, High Power Laser Sci. Engng 2, 1 (2014). 